the kinds of chemical substances which induce cancer and finally the theories which have been propounded to explain the observed facts. The role of viruses and radiation in cancer is discussed only briefly.

There are many occupational and environmental hazards which are known to cause cancer in man although they are diffioult to identify because there is often a latent period of twenty years or so between exposure to particular chemical compounds and the development of the disease. Progress has been occasionally hampered by attempts to suppress knowledge of the hazard. The discovery of causes of cancer is also complicated by the occurrence of spontaneous cancer in men or animals, who are not known to have been exposed to carcinogens. If an individual develops tuberculosis it is certain that he has been infected with the tubercle bacillus; but if a man develops lung eancer it cannot be said with certainty that this was due to exposure to eigarette smoke or to atmospheric pollutants. By examination of the incidence of cancer of the lung in populations it is clearly established that lung cancer is twice as common in larger cities as in the rural areas in Britain, and twenty times higher among heavy smokers as among non-smokers. Lung cancer is also higher among men occupied in copper smelting, in asbestos mining and in chromate workers. There is evidence indicating that some cases of cancer of the skin, bladder, nasal sinuses, bone, peritoneum, and liver in man are caused by external factors which could $b e$ avoided and the incidence of malignant disease at these sites reduced.

The examination of the relationship between chemical structure and the activity of cancer-producing compounds began in the nineteen thirties, when first the activity of polycyclic hydrocarbons related to 3:4-benzopyrene, which was isolated from coal tar, was described. Later heterocyclic polycyclic compounds containing nitrogen or sulphur were shown to be carcinogenic. By 1946 the activity of a sufficient number of compounds was known for theories of the biological action to be put forward; but we still do not know the mechanism of action of these polyeyclic aromatic derivatives. Another important group of chemical carcinogens is the aromatic amines, three of which, 2-naphthylamine, benzidine and 4-aminobiphenyl, cause cancer of the bladder in man. Because the action of these compounds is exerted at sites remote from the point of application, the effect must be due to some metabolic product. Dr. Clayson puts forward evidence in favour of the active metabolites being ortho aminophenols, but more recent work indicates, in my opinion, that arylhydroxylamines are more probably the effective agents.

Still other types of carcinogenic agents, all of which eause liver cancer in rodents, are the azo dyes, one of which, butter yellow, was once added to margarine, pyrrolizidine alkaloids which have been used in folk medicines in many parts of the world, chloroform, an anæsthetic and flavouring agent, carbon tetrachloride which was used in the treatment of hookworm infestation, thiourea used as a preservative for oranges, and nitrosamines of which the simplest and first recognized member is dimethylnitrosamine.

After discussing the different kinds of carcinogen, the author considers the 'two-stage' theory of carcinogenesis, the role of hormones, the significance of binding of carcinogens to proteins, the relationship of chemical carcinogens to the chemotherapy of cancer and the more hypothetical aspects of the problem, including somatic mutation and the immunological concept.

In a final short chapter on future trends the author says rightly that: "It is undesirable that any carcinogenic agent should be allowed to come in contact with man", and then proceeds: "but, to me, it appears that effective control may best be achieved by defining maximum permissive levels and by evolving methods for the analysis of the appropriate levels in the environment".
In many cases this is wrong because the best way of preventing contact with food additives or contaminants is to prevent their use.

Dr. Clayson is to be congratulated on his work, which should be of great help to many people. One of the difficulties about books of this kind is that some parts are out of date because publication takes a long time, and progress in research is rapid. The book is well produced except that the hexagons in chemical formulæ representing benzene rings are elongated in an unusual and unpleasant way.

E. BoYland

\section{RUSSIAN VIEW OF CANCER}

\section{Cancer}

A General Guide to Research and its Treatment. Edited by Prof. N. N. Petrov. Translated by A. P. Fletcher. Pp. xvi +387 . (London and New York: Pergamon Press, 1962.) 80s. net.

CHE purpose of this book, according to the English editor's preface, is to provide a summary of important findings in theoretical, experimental and clinical oncology and to provide Western readers with an adequate introduction to most lines of cancer work being pursued at present, not only in the U.S.S.R. but also throughout the world. It seems to have been written for Russian medical students and doctors interested in theoretical oncology, and is now presented in an excellent English translation. Of the 17 chapters, nine are written by Prof. N. N. Petrov and the remainder by collaborators. The first part of the book is devoted to the pathology of tumours, and comprises definitions, the distribution of tumours in living nature, their spread, morphology and biochemistry, and the factors which influence tumour genesis and growth. Experimental tumour induction and rtiology occupy roughly a quarter of the book. The subject-matter then changes to questions of dirgnosis, prognosis, treatment (operative, radiotherapeutic or chemical), prophylaxis and anti-cancer campaigns. Thus the fields covered are enormous and it is inevitable that their exposition should be cursory and superficial.

The reader of this book steps back into the past. For example, the statistics quoted in defence of the thesis that the incidence of cancer is not rising cease at 1940. It is stated that the case for a relation between smoking and lung cancer has not been proved, the data of Graham (1954) being quoted; but since that time unequivocal statistical evidence has been fortheoming from Britain and other countries. No work on the relation of sex hormones to the induction of mammary cancer beyond that of Lacassagne (started in 1933 and summarized in 1947) is quoted, yet a vast number of important new observations have been made since that time.

Certain omissions demand comment. In 24 pages devoted to a discussion of chemical substances as cancer inducers, the names of Kennaway and his school, famous the world over for the isolation of the first pure carcinogens, are not mentioned. In discussing the two-stage mechanism of carcinogenesis the work of Rous is omitted, and Berenblum and Shubik are quoted only as propounding the theory of the diphasic character of carcinogenesis, in spite of the vast amount of experimental work done by them and their collaborators. These omissions would not be so evident if the lesser contributions of some other workers were not described in extenso.

It is difficult to see what place this book could occupy among British readers. To students and practitioners it would give a one-sided and superficial account of the subjects enumerated above. For experimentalists there are many other deeper and more useful sources of reference. At eighty shillings it is expensive.

Georgiana M. Bonser 